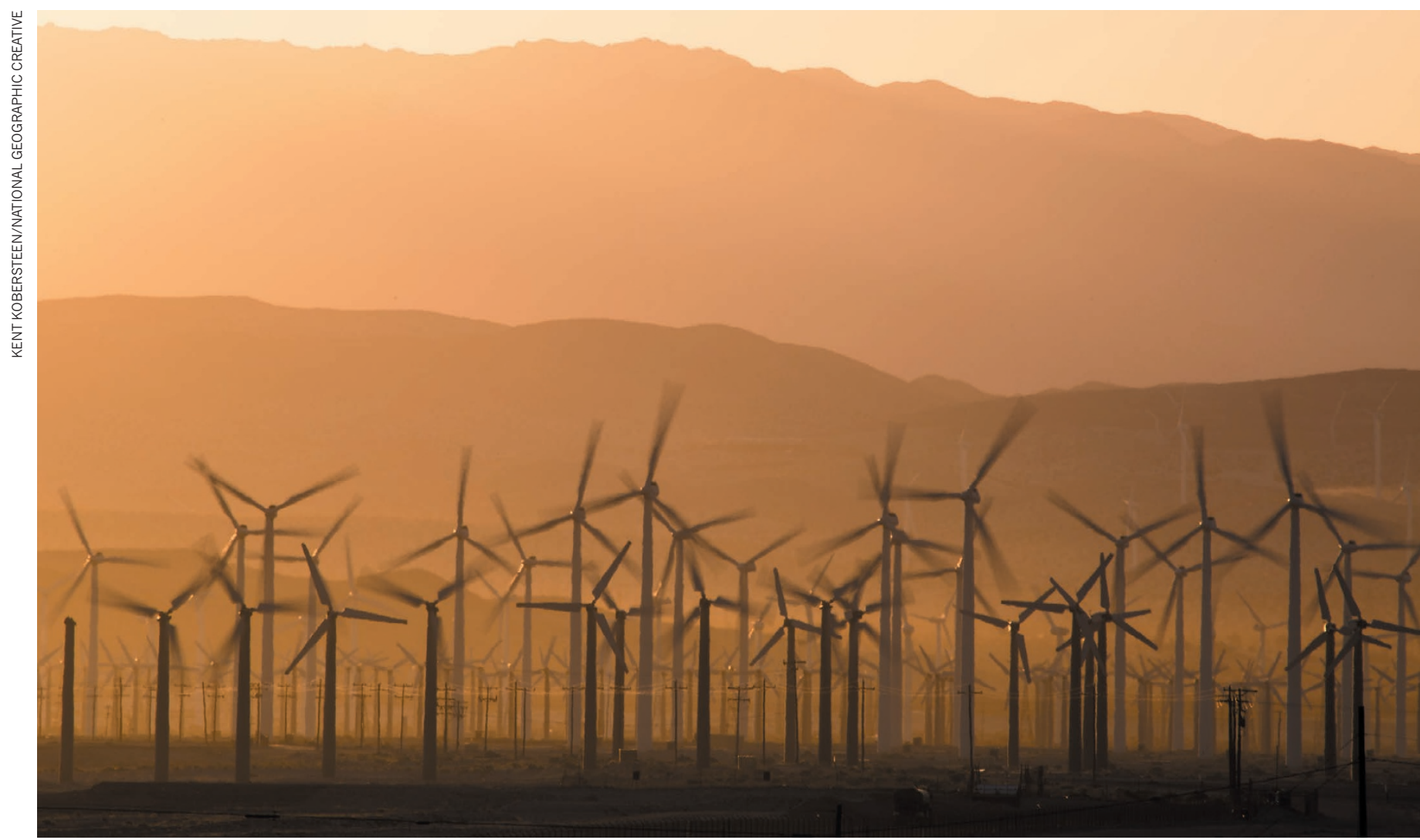

Wind turbines near Palm Springs, California.

\title{
Scanning the energy horizon
}

\section{Michael Grubb finds more breadth than depth in Dieter Helm's study on oil's demise.}

$\mathrm{W}$

ith Burn Out, Dieter Helm — one of the most outspoken and influential commentators on energy - is back, with a big, broad view on the energy revolution. He pokes fun at the "peak oilers", who believe that shrinking fossil-fuel resources will force the transition to renewables. The alternative thesis he offers should send forecasters scurrying back to their models, and set established energy industries quaking in their corporate asset evaluations.

Helm's core argument is that three "predictable surprises" will revolutionize twenty-first-century energy. The commodity boom, or supercycle, of the past 15 years has bust, and will not return. The pressure to decarbonize will increase in the face of overwhelming evidence of climate change. And technological innovation will flourish, with solar-based electricity dominating energy supply. The book's great contribution is to integrate these three megaforces, and explore

\section{$\rightarrow$ NATURE.COM}

For more on science in culture see:

nature.com/

booksandarts their geopolitical and industrial implications.

First, Helm kicks against conventional wisdom on the supercycle, radically concluding that "renormalized" oil prices could continue to fall. Shale-gas extraction technologies, in particular, have advanced so far and fast that they open up a new global resource, yet demand

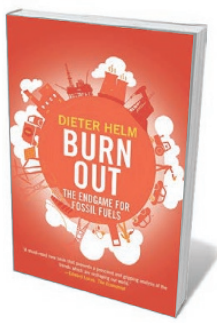

Burn Out: The

Endgame for Fossil Fuels

DIETER HELM

Yale University Press: 2017. may shrink. The International Energy Agency's World Energy Outlook 2016 sees oil prices rising back to US\$78-145 per barrel by 2040 . Helm posits a mere \$40-60 per barrel, long-term.

Thus, the energy problem is not peak oil but peak carbon, the next "predictable surprise". Here, Helm zeroes in on the gulf between climate goals and industry expectations. He notes that climate science and the impacts of climate change will slowly tighten the policy screws. (And one can hardly dispute his independence of mind when he argues that in Europe, "warming by up to $2{ }^{\circ} \mathrm{C}$ will probably do little harm to the main economies... After that, all bets are off.")

His argument on climate policy contains some irritating inconsistencies. He says industry is still not facing up to the realities of carbon control, yet he is scathing about past climate policies. Then, elsewhere in the book, he acknowledges that the same policies have had a major impact on the coal industry and on power generation.

He emphatically supports charging for carbon dioxide emissions but gives a ritual bashing to the 1997 Kyoto Protocol, designed to set a cap and price on $\mathrm{CO}_{2}$ across the industrialized world. He neglects to note that all the countries that stayed in the agreement after the United States and Canada withdrew complied with their commitments, most achieving significant emissions reductions. The 2015 Paris climate agreement Helm deems "good politics" - because it reached 
